\title{
Association between EGFR/KRAS mutation and expression of VEGFA, VEGFR and VEGFR2 in lung adenocarcinoma
}

\author{
XIAO-HAN YUAN ${ }^{1-5^{*}}$, JIE YANG $^{1,3-5^{*}}$, XIN-YUE WANG ${ }^{1,3-5}$, XIAO-LING ZHANG ${ }^{1,3-5}$, \\ TING-TING QIN ${ }^{1,3-5}$ and KAI LI ${ }^{1,3-5}$
}

${ }^{1}$ Tianjin Medical University Cancer Institute and Hospital, National Clinical Research Center for Cancer, Tianjin 300060;

${ }^{2}$ Department of Oncology, The First Affiliated Hospital of Xinxiang Medical University, Weihui, Henan 453100;

${ }^{3}$ Key Laboratory of Cancer Prevention and Therapy; ${ }^{4}$ Tianjin Clinical Research Center for Cancer; ${ }^{5}$ Department of

Thoracic Oncology, Tianjin Lung Cancer Center, Tianjin Cancer Institute and Hospital, Tianjin 300060, P.R. China

Received December 1, 2016; Accepted November 10, 2017

DOI: $10.3892 / \mathrm{ol} .2018 .8901$

\begin{abstract}
Epidermal growth factor receptor (EGFR) and Kirsten rat sarcoma viral oncogene homolog (KRAS) are two of the most notable driver genes in lung cancer, whilst vascular endothelial growth factor (VEGF) signaling serves a critical function in tumor angiogenesis. However, few studies have focused on the potential connection between EGFR/KRAS mutational status, and VEGFA, VEGF receptor (VEGFR)1 and VEGFR2 expression in lung adenocarcinoma. EGFR (exon 19, 20 and 21) and KRAS (exon 2) mutations were detected using an amplification refractory mutation system technique, and the expression of VEGFA, VEGFR1 and VEGFR2 was analyzed using immunohistochemistry in 204 patients with lung adenocarcinoma. Associations between EGFR/KRAS mutational status and VEGFA, VEGFR1, and VEGFR2 expression was analyzed using Pearson $\chi^{2}$ tests. It was revealed that EGFR 21 exon $(\mathrm{P}=0.033)$ and EGFR 20 exon $(\mathrm{P}=0.002)$ mutated tumors exhibited a significantly higher level of expression of VEGFA. EGFR 21 exon mutant tumors additionally demonstrated a significantly higher level of co-expression of VEGFA and VEGFR1 ( $\mathrm{P}<0.001)$. EGFR 19 exon mutation was significantly associated with low levels of VEGFR1 ( $\mathrm{P}=0.008)$. KRAS mutation was significantly associated with a high level of co-expression of VEGFA, VEGFR1 and VEGFR2 ( $\mathrm{P}=0.035)$, but no such association with the individual expression of VEGFA, VEGFR1 or
\end{abstract}

Correspondence to: Professor Kai Li, Department of Thoracic Oncology, Tianjin Lung Cancer Center, Tianjin Cancer Institute and Hospital, 1 Huan Hu West Road, Tianjin 300060, P.R. China E-mail: likai5@medmail.com.cn

*Contributed equally

Key words: lung adenocarcinoma, vascular endothelial growth factor A, vascular endothelial growth factor receptor, epidermal growth factor receptor mutation, Kirsten rat sarcoma viral oncogene homolog mutation, anti-angiogenesis therapy
VEGFR2 was identified. However, neither KRAS or EGFR mutations exhibited an association with the expression of VEGFR2. The present study may help in the treatment of various patients with KRAS or subtype of EGFR mutation with anti-angiogenesis therapy.

\section{Introduction}

Lung cancer is one of the most common cancer types in terms of incidence and mortality at present globally (1), and among all the different types, non-small cell lung cancer (NSCLC) accounts for $80-85 \%$ (2). NSCLC may be characterized by the driver gene mutation, particularly by epidermal growth factor receptor (EGFR) and kirsten rat sarcoma viral oncogene homolog (KRAS) mutations. It has previously been reported that EGFR and KRAS mutation occurs in 59.4 and $7.4 \%$, respectively, of all Asian lung adenocarcinoma cases (3). A number of EGFR tyrosine kinase inhibitors (TKIs) have become the first line therapy for lung adenocarcinoma with sensitive EGFR mutations $(4,5)$. Even though there has been progress in molecular target therapy, the 5-year survival rate remains $<15 \%$ (6), which is largely due to TKI-resistance and metastasis $(7,8)$. For the purpose of improving understanding of the mechanisms of resistance to TKIs, the molecular categorization of patients with EGFR/KRAS mutations in NSCLC is required.

Vascular endothelial growth factor (VEGF) signaling serves a pivotal function in tumor angiogenesis and is associated with an increased tumor recurrence and metastasis (9-12). As a major regulator of angiogenesis, VEGFA binds to the VEGF receptor (VEGFR)1 and VEGFR2, which are important members of the family of receptor tyrosine kinases (RTKs). They stimulate multiple pathways, including mitogen-activated protein kinases, phosphoinositide 3-kinases (PI3Ks), and protein kinase B (Akt) (13-15), to promote recurrence and metastases. VEGFR1 signaling regulates endothelial cell survival and VEGFR2 signaling regulates the differentiation of endothelial cells into capillary tubes (16). By inhibiting the VEGFA-VEGFR signaling pathway, a number of strategies for the therapy of different types of cancer have been established, including bevacizumab, an antibody that targets VEGFA, 
and diverse inhibitors of RTKs. However, recurrence due to resistance to the therapy remains inevitable in a number of tumors $(17,18)$. In order to overcome resistance and combine more rationally the two types of targeted therapy, it is crucial to firstly reveal the association among different driver genes associated with targeted efficacy and drug-resistance.

In the present study, the aim was to establish the association between VEGFA, VEGFR1 and VEGFR2 expression and EGFR/KRAS mutations. Furthermore, this study aimed to determine the potential benefit of TKIs and anti-angiogenesis therapy, and elucidate potential 'cross resistance' occurrences to the aforementioned therapies due to associated driver gene mutations and protein expression in lung adenocarcinoma. It may provide a more improved understanding of how to treat various patients with KRAS or a subtype of the EGFR mutation with anti-angiogenesis therapy.

\section{Materials and methods}

Sample collection. A total of 204 patients with lung adenocarcinoma who underwent surgery at Cancer Hospital of Tianjin Medical University (Tianjin, China) between January 2013 and December 2015 were selected for the study. There were 99 females (48.5\%) and 105 males (51.5\%); 93 patients $(45.6 \%)$ with age $>60$ years and 111 patients $(54.4 \%)$ with age $\leq 60$ years (median age, 58 years; age range $30-76$ years). Collection and use of tumor tissue samples for research received written informed consent from all patients prior to the study and was ethically approved by Ethics and Scientific Committee of Tianjin Medical University Cancer Hospital. Each specimen was confirmed as lung adenocarcinoma by pathological diagnosis. Clinicopathological features of each patient comprised sex, age, smoking status, lymph node metastasis and clinical stage. Tumor clinical stage was identified according to the International Association for the Study of Lung Cancer 2009 TNM tumor staging system (19). Smoking history was marked as either yes or no (patients were defined as non-smokers if they had never smoked in their lifetime).

Immunohistochemistry (IHC). IHC was performed on formalin-fixed paraffin-embedded (FFPE) specimens $(4 \mu \mathrm{m})$ by using antibodies for VEGFA (mouse monoclonal IgG; 1:200; cat no. ab1316), VEGFR1 (rabbit monoclonal IgG; 1:50; cat no. ab32152) (both from Abcam, Cambridge, UK) and VEGFR2 (rabbit monoclonal IgG; 1:200; cat no. 55B11; Cell Signaling Technologies, Inc., Danvers, MA, USA). Following baking in a $65^{\circ} \mathrm{C}$ oven (Fuzhou Maixin Biotech Co., Ltd., Fuzhou, China) for $1 \mathrm{~h}$, the FFPE specimens were deparaffinized in xylene, rehydrated in graded alcohol and then washed with phosphate buffer saline (PBS) three times for $5 \mathrm{~min}$. For the purpose of antigen retrieval, the sections were boiled for $3 \mathrm{~min}$ at $100^{\circ} \mathrm{C}$ in citric acid-based buffer at pH 6.0 for VEGFA antigen and EDTA-based buffer at pH 9.0 for VEGFR1 and VEGFR2 antigens. Then, the slides were cooled to room temperature and rinsed with PBS 3 times for $5 \mathrm{~min}$. Subsequently, the activity of endogenous peroxidase was blocked by $3 \%$ hydrogen peroxide for $20 \mathrm{~min}$ at room temperature, and the slides were incubated with primary antibodies at $4^{\circ} \mathrm{C}$ overnight (for $>12 \mathrm{~h}$ ). Subsequently, slides were rinsed using PBS three times for $5 \mathrm{~min}$ at room temperature and incubated in horseradish peroxidase-conjugated secondary antibodies (Polymer detection kit for mouse and rabbit; used as supplied); PV-6000; OriGene Technologies, Inc. (Beijing, China) for $1 \mathrm{~h}$ at $37^{\circ} \mathrm{C}$. Each section was washed as before and visualized using the chromogen diaminobenzidine. Finally, prior to being dehydrated and mounted, the slides were counterstained with hematoxylin for two min at room temperature and then were observed at x200 magnification using a light microscope.

DNA extraction and amplification-refractory mutation system (ARMS) assay. Each case was analyzed for the presence of EGFR and KRAS mutations. DNA extraction was applied to the FFPE sections, which was performed using a QIAamp DNA FFPE Tissue kit (Qiagen GmbH, Hilden, Germany) according to the manufacturer's protocol. The presence of EGFR and KRAS mutations was detected using the Human EGFR Gene Mutation Detection kit and the Human KRAS Gene Mutation Detection kit (Fluorescent polymerase chain reaction; both from Beijing ACCB Biotech Ltd., Beijing, China), which was approved by the State Food and Drug Administration for clinical application in China. Polymorphisms of the EGFR gene in exon 19 (E19del), 20 (T790M S768I and E20ins) and 21 (L861Q and L858R), and KRAS gene in exon 2 were detected. Analysis of the presence of these mutations was performed using a LightCycler480 (Roche Diagnostic, Basel, Switzerland).

Interpretation of protein expression. Two independent well-experienced pathologists without knowledge of the clinicopathological information of each patient assessed the VEGFA, VEGFR1 and VEGFR2 expression. For the expression of VEGFA and VEGFR1, each slide was evaluated according to the staining intensity and percentage of positive tumor cells. Scores for the staining intensity were classified as 0 (negative), 1 (weak), 2 (moderate) and 3 (strong) (Fig. 1). Scores for the percentage of tumor cells for $0-10,11-25,26-50,51-75$ and $>75 \%$ were classified as $0,1,2,3$ and 4 , respectively. The scores of the staining intensity was multiplied by the scores of the percentage of stained cells $(0-100 \%)$. The finally weighted scores of $0-1,2-3,4-6$ and 7-12 were classified as-,,+++ and +++ , respectively (20). The samples that had weighted scores of $0-1$ were classified as negative expression and the remaining samples which had weighted scores $>2$ were classified as positive expression.

Samples were defined as positive for VEGFR2 cytoplasmic staining when $\geq 5 \%$ of the tumor cells presented weak, moderate or strong expression. Samples were defined as positive for VEGFR2 vascular staining when the number of positive vessels was $>2$ (21). Positive expression of VEGFR2 was defined as either positivity in the tumor cells or in the tumor stromal vasculature.

Statistical analysis. SPSS statistical software (version 17; SPSS, Inc., Chicago, IL, USA) was used for statistical analysis. $\mathrm{P}<0.05$ was considered to indicate a statistically significant difference. Associations between clinicopathological variables (sex, age, smoking status, lymph node metastasis and clinical stage) and EGFR/KRAS mutant status or VEGFA/VEGFR1/VEGFR2 expression were analyzed using Pearson's $\chi^{2}$ tests, which was also used to evaluate the association between VEGFA/VEGFR1/VEGFR2 expression 

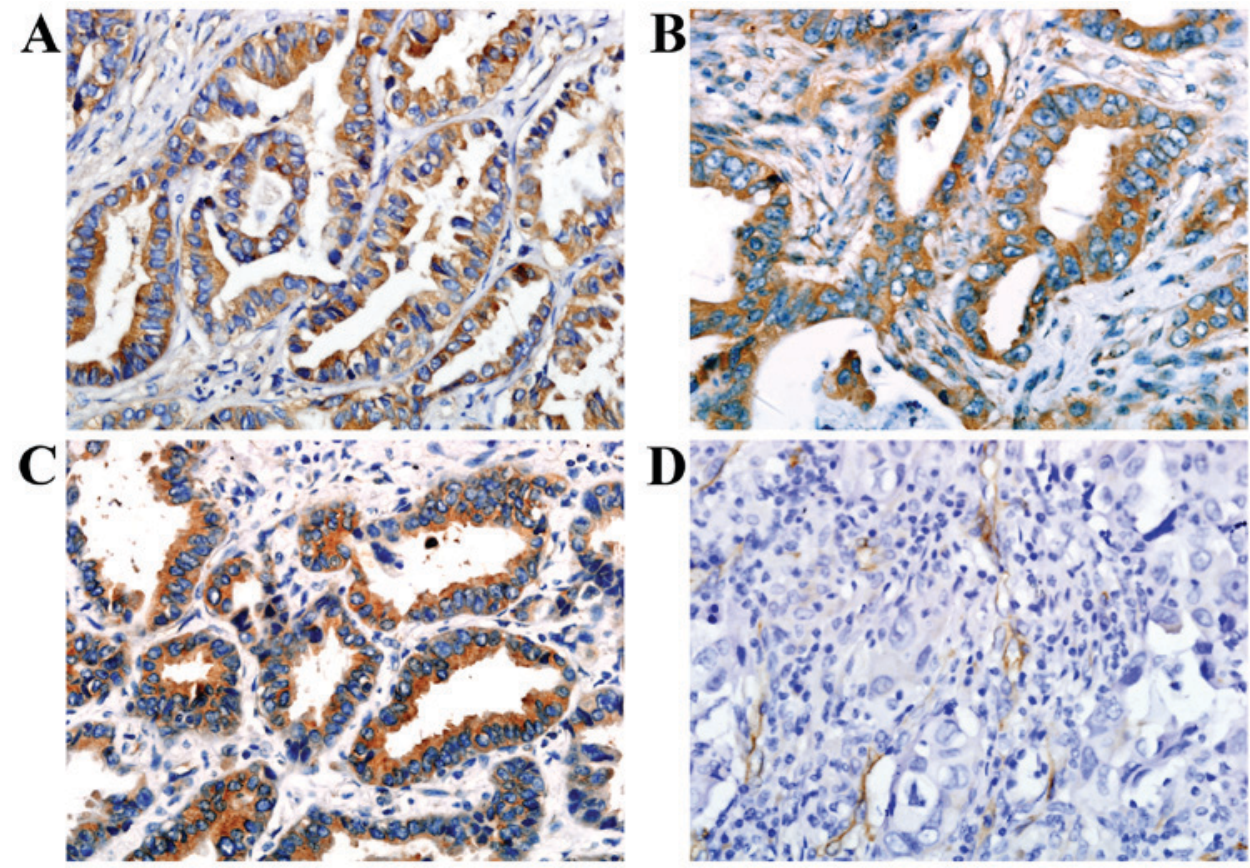

Figure 1. Representative immunohistochemical staining for (A) VEGFA, (B) VEGFR1, and (C and D) VEGFR2 in lung adenocarcinoma tumor tissue VEGFA, and VEGFR1 were predominantly identified in the cytoplasm of tumor cells. VEGFR2 was localized to tumor cell cytoplasm and tumor stromal vasculature. Original magnification, x400. VEGFA, vascular endothelial growth factor A; VEGFR, vascular endothelial growth factor receptor.

and mutations in EGFR and KRAS. The correlation between VEGFA, VEGFR1 and VEGFR2 expression was analyzed using Spearman's rank correlation coefficient.

\section{Results}

VEGFA, VEGFR1 and VEGFR2 expression, and their association with the clinicopathological characteristics of patients with lung adenocarcinoma. VEGFA and VEGFR1 staining were localized primarily to the tumor cell cytoplasm, while VEGFR2 was localized to the tumor cell cytoplasm and tumor stromal vasculature (Fig. 1). Of the 204 adenocarcinoma samples, 140/204 (68.6\%), 141/204 (69.1\%) and 98/204 (48.0\%) were identified as for positive VEGFA, VEGFR1 and VEGFR2 expression, respectively. No significant associations were revealed between the expression of each and age, sex, smoking history, lymph node metastasis or clinical stage (Table I). Of all VEGFR1 positive cases, 77/141 (54.6\%) exhibited VEGFR2 positive expression. Of all VEGFR1 negative cases, 42/63 (66.7\%) exhibited VEGFR2 negative expression. VEGFR1 expression was significantly correlated with VEGFR2 expression $(\mathrm{r}=0.247$; $\mathrm{P}<0.001$; Table II). However, no associations between VEGFA expression and its receptors were revealed.

EGFR/KRAS mutations and the association with the clinicopathological characteristics of patients with lung adenocarcinoma. Among the total 204 cases, 104 (51.0\%) mutated EGFR and 19 (9.3\%) mutated KRAS (exon 2) were identified. Of the 104 cases, there were 44 exon-19 mutations, 13 exon-20 mutations and 47 exon- 21 mutations.

In female patients, EGFR mutation frequency was $62.6 \%$ (62/99) which was significantly higher compared with male patients $(40.0 \%$; $42 / 105 ; \mathrm{P}=0.001)$, and in non-smokers, the frequency of EGFR mutations was $63.0 \%$ (68/108) which was significantly higher compared with smokers $(37.5 \%$; 36/96; $\mathrm{P}<0.001)$. It was concluded that there was a significant association between EGFR mutation status and sex and smoking history, but there was no notable association between EGFR mutations and age, lymph node metastasis, or clinical stage involvement (Table II). In male patients, KRAS mutation frequency was $13.3 \%(14 / 105)$ which was significantly higher compared with female patients $(5.1 \% ; 5 / 99 ; \mathrm{P}=0.042)$ and in smokers, the frequency of KRAS mutations was $13.5 \%$ (13/96) which was significantly higher compared with non-smokers $(5.6 \%, 6 / 108 ; \mathrm{P}=0.050)$. It was concluded that there were significant associations between KRAS mutation status and sex and smoking history. However, there was no significant association identified between KRAS mutation status and age, lymph node metastasis or clinical stage involvement (Table III).

Correlation between each subtype of EGFR mutation and the expression of VEGFA, VEGFR1 and VEGFR2. EGFR 20 and 21 exon mutation frequency in VEGFA-positive samples was $8.6 \%$ (12/140) and 29.3\% (41/140), respectively. This was significantly higher compared with in the VEGFA-negative samples $(1.6 \%, 1 / 64 ; \mathrm{P}=0.033)$ and $(9.4 \%, 6 / 64 ; \mathrm{P}=0.002)$. EGFR 19 exon mutation frequency in VEGFA-positive samples was $20.0 \%$ (28/140), which was insignificantly lower compared with VEGFA-negative samples $(25.0 \%$; 16/64; $\mathrm{P}=0.420$ ). Additionally, the EGFR 19 exon mutation frequency in VEGFR1-positive samples was $15.6 \%$ (22/141), significantly lower compared with VEGFR1-negative samples (31.7\%; 20/63; $\mathrm{P}=0.008$ ). A high level of VEGFA and VEGFR1 co-expression was significantly correlated with EGFR 21 exon mutation $(\mathrm{P}<0.001)$. However, there was no significant associations between VEGFR2 expression or the co-expression of VEGFA/VEGFR1/VEGFR2 and each subtype of EGFR mutation status (Table IV). 
Table I. Association between clinicopathological characteristics and VEGFA, VEGFR1 or VEGFR2 expression in patients with lung adenocarcinoma.

\begin{tabular}{|c|c|c|c|c|c|c|c|}
\hline \multirow[b]{2}{*}{$\begin{array}{l}\text { Clinicopathological } \\
\text { characteristics }\end{array}$} & \multirow[b]{2}{*}{ No. } & \multicolumn{2}{|c|}{ VEGFA } & \multicolumn{2}{|c|}{ VEGFR1 } & \multicolumn{2}{|c|}{ VEGFR2 } \\
\hline & & $\begin{array}{l}\text { Positive } \\
\text { No. (\%) }\end{array}$ & P-value & $\begin{array}{l}\text { Positive } \\
\text { No. }(\%)\end{array}$ & P-value & $\begin{array}{l}\text { Positive } \\
\text { No. }(\%)\end{array}$ & P-value \\
\hline \multicolumn{8}{|l|}{ Sex } \\
\hline Male & 105 & $67(63.8)$ & 0.127 & 71 (67.6) & 0.633 & 49 (46.7) & 0.686 \\
\hline Female & 99 & 73 (73.7) & & $70(70.7)$ & & 49 (49.5) & \\
\hline \multicolumn{8}{|l|}{ Age (years) } \\
\hline$\leq 60$ & 111 & $80(72.1)$ & 0.247 & $78(70.3)$ & 0.697 & $50(45.0)$ & 0.350 \\
\hline$>60$ & 93 & $60(72.1)$ & & $63(67.7)$ & & $48(51.6)$ & \\
\hline \multicolumn{8}{|l|}{ Smoking history } \\
\hline Non-smokers & 108 & $80(72.1)$ & 0.075 & $74(68.5)$ & 0.844 & $53(49.1)$ & 0.754 \\
\hline Smokers & 96 & $60(62.5)$ & & $67(69.8)$ & & 45 (46.9) & \\
\hline \multicolumn{8}{|c|}{ Lymph node metastasis } \\
\hline Absent & 135 & $91(67.4)$ & 0.599 & 97 (71.9) & 0.237 & 68 (50.4) & 0.351 \\
\hline Present & 69 & $49(70.1)$ & & $44(63.8)$ & & $30(43.5)$ & \\
\hline \multicolumn{8}{|l|}{ TNM stage } \\
\hline $\mathrm{I}+\mathrm{II}$ & 141 & $95(67.4)$ & 0.727 & $102(72.3)$ & 0.136 & $68(48.2)$ & 0.936 \\
\hline III & 63 & $44(69.8)$ & & 39 (61.9) & & $30(47.6)$ & \\
\hline I & 120 & $80(66.7)$ & 0.471 & $87(72.5)$ & 0.211 & $59(49.2)$ & 0.700 \\
\hline II+III & 84 & $60(71.4)$ & & $54(64.3)$ & & $39(46.4)$ & \\
\hline
\end{tabular}

TNM, tumor-node-metastasis; VEGFA, vascular endothelial growth factor A; VEGFR, vascular endothelial growth factor receptor.

Association between KRAS mutation, and the expression of VEGFA, VEGFR1 and VEGFR2. KRAS mutation frequency in the VEGFA-positive samples was $10.0 \%$ (14/140), which was higher compared with the negative samples $(7.8 \% ; 5 / 64)$, but with no statistical significance between them $(\mathrm{P}=0.618)$. KRAS mutation frequency in the VEGFR1-positive samples was $11.3 \%$ (16/141), which was insignificantly higher compared with the VEGFR1-negative samples $(4.8 \%$; 3/63) $(\mathrm{P}=0.114)$. KRAS mutation frequency in the VEGFR2-positive samples was $12.2 \%$ (12/98), being insignificantly higher compared with the VEGFR2 samples $(6.6 \% ; 7 / 106)(\mathrm{P}=0.166)$. However, it was revealed that a high level of co-expression of VEGFA, VEGFR1 and VEGFR2 was significantly associated with KRAS mutation $(\mathrm{P}=0.035$; Table IV).

\section{Discussion}

According to characterizations by the driver gene mutation, patients with NSCLC have different features and may benefit from targeted therapies. There has been great improvements in the targeted therapeutic outcome for selected patient groups based on driver gene mutations (22). However, the application of TKIs remains with numerous limitations at present. A majority of patients with KRAS or EGFR (exon 20) mutations may not benefit from EGFR inhibition (23-25). Meanwhile, due to the complex network that drives KRAS tumors, a combinatorial multi-target/multi-pathway inhibitory approach may be necessary to modulate cell growth in patients with KRAS mutant NSCLC (26-30). The present study focused on
Table II. Correlation between VEGFR1 and VEGFR2 expression in lung adenocarcinoma.

\begin{tabular}{lcrrrr}
\hline & \multicolumn{2}{c}{ VEGFR2 } & & & \\
\cline { 2 - 4 } VEGFR1 & Negative & Positive & Total & $r_{\mathrm{s}}$ & P-value \\
\hline- & 42 & 21 & 63 & 0.247 & $\mathrm{P}<0.001$ \\
+ & 17 & 9 & 26 & & \\
++ & 19 & 23 & 42 & & \\
+++ & 28 & 45 & 73 & & \\
Total & 106 & 98 & 204 & & \\
\hline
\end{tabular}

VEGFR, vascular endothelial growth factor receptor.

EGFR/KRAS mutations in patients with lung adenocarcinoma and the expression of a number of angiogenic proteins, and analyzed the clinicopathological features of these patients in order to better define their characteristics. It may provide further evidence for the use of certain molecular markers for targeted therapy, namely EGFR/KRAS, VEGFA, VEGFR1 and VEGFR2.

In all 204 cases of patients with lung adenocarcinoma included in the present study, high expression rates of VEGFA (68.6\%), VEGFR1 (69.1\%) and VEGFR2 (48\%) were identified. The mutation rates of EGFR exons (19-21) and KRAS exon 2 were 51.0 and $9.3 \%$, respectively. The proportion of exon 19 , 
Table III. Association between clinicopathological characteristics and EGFR and KRAS mutations in patients with lung adenocarcinoma.

\begin{tabular}{|c|c|c|c|c|c|}
\hline \multirow{2}{*}{$\begin{array}{l}\text { Clinicopathological } \\
\text { characteristics }\end{array}$} & \multirow[b]{2}{*}{ No. } & \multicolumn{2}{|c|}{ Mutant EGFR } & \multicolumn{2}{|c|}{ Mutant KRAS } \\
\hline & & No. $(\%)$ & P-value & No. $(\%)$ & P-value \\
\hline \multicolumn{6}{|l|}{ Sex } \\
\hline Male & 105 & $42(40.0)$ & 0.001 & $14(13.3)$ & 0.042 \\
\hline Female & 99 & $62(62.6)$ & & $5(5.1)$ & \\
\hline \multicolumn{6}{|l|}{ Age (years) } \\
\hline$\leq 60$ & 111 & $58(52.3)$ & 0.691 & $5(4.5)$ & 0.100 \\
\hline$>60$ & 93 & $46(49.5)$ & & $14(15.1)$ & \\
\hline \multicolumn{6}{|l|}{ Smoking history } \\
\hline Non-smokers & 108 & $68(63.0)$ & $<0.001$ & $6(5.6)$ & 0.050 \\
\hline Smokers & 96 & $36(37.5)$ & & $13(13.5)$ & \\
\hline \multicolumn{6}{|c|}{ Lymph node metastasis } \\
\hline Absent & 135 & $71(52.6)$ & 0.519 & $11(8.1)$ & 0.423 \\
\hline Present & 69 & $33(47.8)$ & & 8 (11.6) & \\
\hline \multicolumn{6}{|l|}{ TNM stage } \\
\hline $\mathrm{I}+\mathrm{II}$ & 141 & $73(51.8)$ & 0.735 & $14(9.9)$ & 0.651 \\
\hline III & 63 & $31(49.2)$ & & $5(7.9)$ & \\
\hline I & 120 & $65(54.2)$ & 0.277 & $10(8.3)$ & 0.565 \\
\hline II+III & 84 & $39(46.4)$ & & $9(10.7)$ & \\
\hline
\end{tabular}

TNM, tumor-node-metastasis; EGFR, epidermal growth factor receptor; KRAS, Kirsten rat sarcoma viral oncogene homolog.

20 and 21 mutations were $21.6,6.4$ and $23.0 \%$, respectively. Consistent with previous studies $(3,31)$, EGFR mutations occur more frequently in non-smokers and female patients, and KRAS mutations exist more commonly in smokers and male patients. It was revealed that the expression of VEGFR1 was significantly correlated with that of VEGFR2. However, no associations were revealed between the expression of VEGFA and receptors.

Reinmuth et al (32) observed that mutant EGFR tumors, without exposing mutant subtypes, represented a higher level of VEGFA expression. Clarke et al (33) demonstrated that mutant EGFR enhanced the induction of VEGF by hypoxia and insulin-like growth factor-1 via a PI3 kinase-dependent pathway. However, the association between different subtypes of EGFR mutation status and VEGFA or RTK expression have seldom been revealed. In the present study, it was revealed that all patients with lung adenocarcinoma harboring either EGFR 20 or 21 exon mutations had a high level of VEGFA expression. However, there was no association between EGFR 19 mutation and VEGFA expression. It may provide the suggestion that patients harboring either EGFR 20 or 21 exon mutations ought to have the priority of anti-VEGFA targeted therapy.

In the present study, it was observed that the high level of co-expression of VEGFA and VEGFR1 were significantly associated with the EGFR 21 mutation. Zhang et al (16) revealed that VEGF-induced accumulation of VEGFR1 occurs through Akt and ERK signaling. Owing to the high level of co-expression of VEGFA and VEGFR1, it may provide the potential for EGFR 21 mutant patients to receive inhibitors of the Akt and ERK signaling pathway to downregulate
VEGFR1, which further reduces the combination of VEGFA and VEGFR1. Notably, it was identified that the EGFR 19 exon mutation frequency in the VEGFA-positive cases was only $20 \%(28 / 140)$, lower compared with that in the negative samples $(25 \%, 16 / 64)$, despite the lack of statistical significance between them $(\mathrm{P}=0.42)$. In addition, lower VEGFR1 expression was significantly associated with the EGFR 19 exon mutation. Liu et al (34) demonstrated that compared with patients with EGFR exon 21 mutations, patients with EGFR exon 19 mutations exhibit an increased objective response rate, progression-free survival time and overall survival time following EGFR-TKI therapy. Further studies may be required to explore whether there is a potential association between the two phenomena.

Additionally, there was no significant association identified between VEGFR2 expression and each subtype of EGFR or KRAS mutation. To the best of our knowledge, only a few previous studies have reported the potential association between KRAS gene status and RTK (VEGFR1 and VEGFR2) expression $(35,36)$, and there were no associated reports on the correlation of EGFR gene status and RTK (VEGFR1 and VEGFR2) expression. Schimanski et al (35) found that KRAS mutation can increase the expression of VEGFR1 and VEGFR2 in colorectal cancer, but the mechanisms remain unknown. Further validation of the associations identified between RTK expression, EGFR and KRAS mutant status in a larger cohort of patients with lung adenocarcinoma, in addition to further studies on the mechanism are warranted.

A number of studies have reported that VEGFA expression may be upregulated by oncogene activation of KRAS in 
Table IV. Association between subtype of EGFR/KRAS mutation and expression of VEGFA, VEGFR1 and VEGFR2 in lung adenocarcinoma.

\begin{tabular}{|c|c|c|c|c|c|c|c|c|c|}
\hline \multirow[b]{3}{*}{ Protein } & \multirow[b]{3}{*}{ No. } & \multicolumn{4}{|c|}{ Mutant EGFR } & \multicolumn{4}{|c|}{ Mutant KRAS } \\
\hline & & \multicolumn{2}{|c|}{ EGFR 19 exon } & \multicolumn{2}{|c|}{ EGFR 20 exon } & \multicolumn{2}{|c|}{ EGFR 21 exon } & \multicolumn{2}{|c|}{ KRAS 2 exon } \\
\hline & & No. $(\%)$ & P-value & No. (\%) & P-value & No. $(\%)$ & P-value & No. $(\%)$ & P-value \\
\hline \multicolumn{10}{|l|}{ VEGFA } \\
\hline Positive & 140 & $28(20.0)$ & 0.420 & $12(8.6)$ & 0.033 & $41(29.3)$ & 0.002 & $14(10.0)$ & 0.618 \\
\hline Negative & 64 & $16(25.0)$ & & $1(1.6)$ & & $6(9.4)$ & & $5(7.8)$ & \\
\hline \multicolumn{10}{|l|}{ VEGFR1 } \\
\hline Positive & 141 & $22(15.6)$ & 0.008 & $7(5.0)$ & 0.233 & $36(25.5)$ & 0.206 & $16(11.3)$ & 0.114 \\
\hline Negative & 63 & $20(31.7)$ & & $6(9.5)$ & & $11(17.5)$ & & $3(4.8)$ & \\
\hline \multicolumn{10}{|l|}{ VEGFR2 } \\
\hline Positive & 98 & $23(23.5)$ & 0.526 & $7(7.1)$ & 0.665 & $23(23.5)$ & 0.776 & $12(12.2)$ & 0.166 \\
\hline Negative & 106 & $21(19.8)$ & & $6(5.7)$ & & 24 (22.6) & & $7(6.6)$ & \\
\hline \multicolumn{10}{|c|}{ VEGFA/VEGFR $1^{\text {a }}$} \\
\hline Positive & 87 & $14(16.1)$ & 0.101 & $8(9.2)$ & 0.792 & $30(34.5)$ & $<0.001$ & $12(13.8)$ & 0.058 \\
\hline Negative & 117 & $30(25.6)$ & & $7(6.0)$ & & $17(14.5)$ & & $7(6.0)$ & \\
\hline \multicolumn{10}{|c|}{ VEGFA/VEGFR1/VEGFR2 ${ }^{\mathrm{b}}$} \\
\hline Positive & 53 & $9(17.0)$ & 0.345 & $4(7.5)$ & 0.689 & $15(28.3)$ & 0.290 & $9(16.7)$ & 0.035 \\
\hline Negative & 151 & $35(23.2)$ & & $9(6.0)$ & & $32(21.2)$ & & $10(6.6)$ & \\
\hline
\end{tabular}

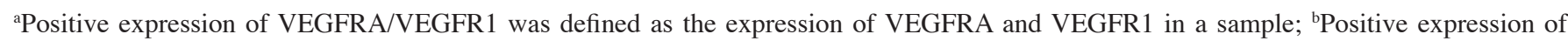
VEGFA/VEGFR1/VEGFR2 was defined as the co-expression of VEGFA, VEGFR1 and VEGFR2 in a sample. EGFR, epidermal growth factor receptor; KRAS, Kirsten rat sarcoma viral oncogene homolog; VEGFA, vascular endothelial growth factor A; VEGFR, vascular endothelial growth factor receptor.

different tumor types (37) and KRAS mutation upregulates VEGF through PI3K-dependent pathways in colon cancer cells (38). However, in the present study, no significant association between KRAS mutation status and individual expression of VEGFA, VEGFR1 or VEGFR2 was identified. Notably, the co-expression of VEGFA, VEGFR1 and VEGFR2 presented in $26 \%$ of the cases, and demonstrated a statistically significant association with the presence of KRAS mutations $(16.7 \%$ with KRAS mutations vs. $6.6 \%$ with KRAS wild type). The different results from previous studies may be ascribed to a number of reasons. First, the pathological features varied among different studies, and retrospectively collected data resulted in a potential bias, such as selection bias. Second, the heterogeneity of tumor tissue among studies resulted in different conclusions. Finally, it suggests that only in a number of 'more active' neoplasms with KRAS stimulation may evident associations be identified between KRAS gene and numerous proteins, including VEGFA and RTKs.

Conclusively, the upregulation of VEGFA may be associated with different types of EGFR mutation. Low level expression of VEGFR1 is more likely to be associated with EGFR 19 exon mutations. High level co-expression of VEGFA and VEGFR1 is associated with EGFR 21 exon mutations, and the high level of co-expression of VEGFA, VEGFR1 and VEGFR2 is associated with KRAS mutations. It remains requisite to evaluate the exact benefit of anti-angiogenesis therapy in patients with different RTK expression. However, confirmation of the different subtypes of EGFR and KRAS mutation status may provide the reference to predict anti-angiogenesis therapeutic effects, and the resistance by neoplasm.

\section{Acknowledgements}

Not applicable.

\section{Funding}

The present study was supported by the Tianjin Municipal Science and Technology Commission Project (grant nos. 11JCYBJC11300 and 12ZCDZSY15600), the CSCO Project (grant no. Y-S2014-011) and the Tianjin Municipal Key Technology R\&D Program of the Ministry of Science and Technology (grant no. 13ZCZCSY20300).

\section{Availability of data and materials}

The datasets used and/or analyzed during the current study are available from the corresponding author on reasonable request.

\section{Authors' contributions}

KL and XY contributed to the conception and design of the study and wrote the manuscript. XY,JY, XZ and TQ performed the experiments. XY, KL and XW analyzed clinical data, and 
KL performed quality control. All authors reviewed the manuscript and approved the final authorship.

\section{Ethics approval and consent to participate}

This study was approved by the Ethics and Scientific Committee of Tianjin Medical University Cancer Hospital. According to the rules set by the Declaration of Helsinki, all patients knew the purpose of the study. Collection and use of tumor tissue samples for research received written informed consent from all patients prior to the study.

\section{Consent for publication}

Not applicable.

\section{Competing interests}

The authors declare that they have no competing interests.

\section{References}

1. Parkin DM, Bray F, Ferlay J and Pisani P: Global cancer statistics, 2002. CA Cancer J Clin 55: 74-108, 2005.

2. Siegel R, Ma J, Zou Z and Jemal A: Cancer statistics, 2014. CA Cancer J Clin 64: 9-29, 2014.

3. Li S, Choi YL, Gong Z, Liu X, Lira M, Kan Z, Oh E, Wang J, Ting JC, Ye X, et al: Comprehensive characterization of oncogenic drivers in asian lung adenocarcinoma. J Thorac Oncol 11: 2129-2140, 2016

4. Maemondo M, Inoue A, Kobayashi K, Sugawara S, Oizumi S, Isobe H, Gemma A, Harada M, Yoshizawa H, Kinoshita I, et al: Gefitinib or chemotherapy for non-small-cell lung cancer with mutated EGFR. N Engl J Med 362: 2380-2388, 2010.

5. Rosell R, Carcereny E, Gervais R, Vergnenegre A, Massuti B, Felip E, Palmero R, Garcia-Gomez R, Pallares C, Sanchez JM, et al: Erlotinib versus standard chemotherapy as first-line treatment for European patients with advanced EGFR mutation-positive non-small-cell lung cancer (EURTAC): A multicentre, open-label, randomised phase 3 trial. Lancet Oncol 13: 239-246, 2012.

6. Sun S, Schiller JH, Spinola M and Minna JD: New molecularly targeted therapies for lung cancer. J Clin Invest 117: 2740-2750, 2007.

7. Mantovani A, Romero P, Palucka AK and Marincola FM: Tumour immunity: Effector response to tumour and role of the microenvironment. Lancet 371: 771-783, 2008.

8. Solan MJ and Werner-Wasik M: Prognostic factors in non-small cell lung cancer. Semin Surg Oncol 21: 64-73, 2003.

9. Ferrara N: The role of VEGF in the regulation of physiological and pathological angiogenesis. Exs: 209-231, 2005.

10. Mattern J, Koomagi R and Volm M: Association of vascular endothelial growth factor expression with intratumoral microvessel density and tumour cell proliferation in human epidermoid lung carcinoma. Br J Cancer 73: 931-934, 1996.

11. Seto T, Higashiyama M, Funai H, Imamura F, Uematsu K, Seki N, Eguchi K, Yamanaka T and Ichinose Y: Prognostic value of expression of vascular endothelial growth factor and its flt-1 and KDR receptors in stage I non-small-cell lung cancer. Lung Cancer 53: 91-96, 2006.

12. Hicklin DJ and Ellis LM: Role of the vascular endothelial growth factor pathway in tumor growth and angiogenesis. J Clin Oncol 23: 1011-1027, 2005.

13. Lohela M, Bry M, Tammela T and Alitalo K: VEGFs and receptors involved in angiogenesis versus lymphangiogenesis. Curr Opin Cell Biol 21: 154-165, 2009.

14. Coultas L, Chawengsaksophak K and Rossant J: Endothelial cells and VEGF in vascular development. Nature 438: 937-945, 2005.

15. Shibuya M: Differential roles of vascular endothelial growth factor receptor-1 and receptor-2 in angiogenesis. J Biochem Mol Biol 39: 469-478, 2006.
16. Zhang Z, Neiva KG, Lingen MW, Ellis LM and Nor JE: VEGF-dependent tumor angiogenesis requires inverse and reciprocal regulation of VEGFR1 and VEGFR2. Cell Death Differ 17: 499-512, 2010.

17. Kowanetz M and Ferrara N: Vascular endothelial growth factor signaling pathways: Therapeutic perspective. Clin Cancer Res 12: 5018-5022, 2006.

18. Ellis LM and Hicklin DJ: VEGF-targeted therapy: Mechanisms of anti-tumour activity. Nat Rev Cancer 8: 579-591, 2008.

19. Chansky K, Sculier JP, Crowley JJ, Giroux D, Van Meerbeeck J and Goldstraw P; International Staging Committee and Participating Institutions: The International Association for the study of lung cancer staging project. Prognostic factors and pathologic TNM stage in surgically managed non-small cell lung cancer. Zhongguo Fei Ai Za Zhi 4: 792-801, 2009 (In Chinese).

20. Chen P, Zhu J, Liu DY, Li HY, Xu N and Hou M: Over-expression of survivin and VEGF in small-cell lung cancer may predict the poorer prognosis. Med Oncol 31: 775, 2014.

21. Holzer TR, Fulford AD, Reising LO, Nedderman DM, Zhang X, Benjamin LE, Schade AE and Nasir A: Profiling of vascular endothelial growth factor receptor heterogeneity identifies protein expression-defined subclasses of human non-small cell lung carcinoma. Anticancer Res 36: 3277-3288, 2016.

22. de Mello RA, Madureira P, Carvalho LS, Araújo A, O Brien M and Popat S: EGFR and KRAS mutation, and ALK fusioin: Current developments and personalized therapies for patients with advanced non-small-cell ling cancer. Pharmacogenomics 14: 1765-1777, 2013.

23. Paez JG, Jänne PA, Lee JC, Tracy S, Greulich H, Gabriel S, Herman P, Kaye FJ, Lindeman N, Boggon TJ, et al: EGFR mutations in lung cancer: Correlation with clinical response to gefitinib therapy. Science 304: 1497-1500, 2004.

24. Lynch TJ, Bell DW, Sordella R, Gurubhagavatula S, Okimoto RA, Brannigan BW, Harris PL, Haserlat SM, Supko JG, Haluska FG, et al: Activating mutations in the epidermal growth factor receptor underlying responsiveness of non-small-cell lung cancer to gefitinib. N Engl J Med 350: 2129-2139, 2004.

25. Mitsudomi T, Kosaka T, Endoh H, Horio Y, Hida T, Mori S, Hatooka S, Shinoda M, Takahashi T and Yatabe Y: Mutations of the epidermal growth factor receptor gene predict prolonged survival after gefitinib treatment in patients with non-small-cell lung cancer with postoperative recurrence. J Clin Oncol 23: 2513-2520, 2005.

26. E J, Xing J, Gong H, He J and Zhang W: Combine MEK inhibition with $\mathrm{PI} 3 \mathrm{~K} / \mathrm{mTOR}$ inhibition exert inhibitory tumor growth effect on KRAS and PIK3CA mutation CRC xenografts due to reduced expression of VEGF and matrix metallopeptidase-9. Tumour Biol 36: 1091-1097, 2015.

27. Hirai H, Sootome H, Nakatsuru Y, Miyama K, Taguchi S, Tsujioka K, Ueno Y, Hatch H, Majumder PK, Pan BS and Kotani H: MK-2206, an allosteric Akt inhibitor, enhances antitumor efficacy by standard chemotherapeutic agents or molecular targeted drugs in vitro and in vivo. Mol Cancer Ther 9: 1956-1967, 2010.

28. Engelman JA, Chen L, Tan X, Crosby K, Guimaraes AR, Upadhyay R, Maira M, McNamara K, Perera SA, Song Y, et al: Effective use of PI3K and MEK inhibitors to treat mutant Kras G12D and PIK3CA H1047R murine lung cancers. Nat Med 14: 1351-1356, 2008

29. Meng J, Dai B, Fang B, Bekele BN, Bornmann WG, Sun D, Peng Z, Herbst RS, Papadimitrakopoulou V, Minna JD, et al: Combination treatment with MEK and AKT inhibitors is more effective than each drug alone in human non-small cell lung cancer in vitro and in vivo. PLoS One 5: e14124, 2010.

30. Corcoran RB, Cheng KA, Hata AN, Faber AC, Ebi H, Coffee EM, Greninger P, Brown RD, Godfrey JT, Cohoon TJ, et al: Synthetic lethal interaction of combined BCL-XL and MEK inhibition promotes tumor regressions in KRAS mutant cancer models. Cancer Cell 23: 121-128, 2013.

31. de Mello RA, Marques DS, Medeiros R and Araujo AM: Epidermal growth factor receptor and K-Ras in non-small cell lung cancer-molecular pathways involved and targeted therapies. World J Clin Oncol 2: 367-376, 2011.

32. Reinmuth N, Jauch A, Xu EC, Muley T, Granzow M, Hoffmann H, Dienemann H, Herpel E, Schnabel PA, Herth FJ, et al: Correlation of EGFR mutations with chromosomal alterations and expression of EGFR, ErbB3 and VEGF in tumor samples of lung adenocarcinoma patients. Lung Cancer 62: 193-201, 2008.

33. Clarke K, Smith K, Gullick WJ and Harris AL: Mutant epidermal growth factor receptor enhances induction of vascular endothelial growth factor by hypoxia and insulin-like growth factor-1 via a PI3 kinase dependent pathway. Br J Cancer 84: 1322-1329, 2001. 
34. Liu Y, Ren Z, Wang J and Zhang S: Epidermal growth factor receptor-tyrosine kinase inhibitor therapy is especially beneficial to patients with exon 19 deletion compared with exon 21 L858R mutation in non-small-cell lung cancer: Systematic review and meta analysis. Thorac Cancer 7: 406-414, 2016.

35. Schimanski CC, Zimmermann T, Schmidtmann I, Gockel I, Lang H, Galle PR, Moehler M and Berger MR: K-ras mutation status correlates with the expression of VEGFR1, VEGFR2, and PDGFRalpha in colorectal cancer. Int J Colorectal Dis 25: 181-186, 2010.

36. Mancikova $V$, Inglada-Pérez $L$, Curras-Freixes $M$, de Cubas AA, Gómez A, Letón R, Kersten I, Leandro-García LJ, Comino-Méndez I, Apellaniz-Ruiz M, et al: VEGF, VEGFR3, and PDGFRB protein expression is influenced by RAS mutations in medullary thyroid carcinoma. Thyroid 24: 1251-1255, 2014.
37. Krajnović M, Marković B, Knežević-Ušaj S, Nikolić I, Stanojević M, Nikolić V, Šiljić M, Jovanović Ćupić S and Dimitrijević B: Locally advanced rectal cancers with simultaneous occurrence of KRAS mutation and high VEGF expression show invasive characteristics. Pathol Res Pract 212: 598-603, 2016.

38. Kang YH, Kim KS, Yu YK, Lim SC, Kim YC and Park KO: The relationship between microvessel count and the expression of vascular endothelial growth factor, p53, and K-ras in non-small cell lung cancer. J Korean Med Sci 16: 417-423, 2001.

c) (i) () () This work is licensed under a Creative Commons Attribution-NonCommercial-NoDerivatives 4.0 International (CC BY-NC-ND 4.0) License. 